crotração de resinas acrílicas de rebasamento, após um processo de envelhecimento químico. Materiais e métodos: Foram selecionadas concentrações de CHX e incorporadas em três resinas acrílicas de rebasamento: $2,5 \%(\mathrm{~m} / \mathrm{m})$ em Kooliner e $5 \%(\mathrm{~m} / \mathrm{m})$ em Ufi Gel Hard e em Probase Cold. Para cada material, foi estabelecido um grupo controlo em que a resina não foi incorporada com CHX. Para o teste de energia à superfície, espécimes com dimensões iguais a 25x16x1 mm (n=7) foram preparados a partir de um molde aço. Para o teste de resistência adesiva à microtração, a resina de rebasamento foi aplicada sobre resina de base protética previamente envelhecida (2500 ciclos termociclagem), de forma a obter 36 paralelepípedos $(n=6)$. Estes foram seccionados nas direções X e Y de forma a obter palitos com $1 \mathrm{~mm} 2$ de área seccional. Todos os espécimes foram imersos em saliva artificial $(1 \mathrm{~g} / 5 \mathrm{~mL})$ e incubados a 37. ${ }^{\circ} \mathrm{C}$ (300 rpm), mimetizando um processo de envelhecimento químico durante 28 dias, com ciclos alternados de $6 \mathrm{~h} \mathrm{em}$ $\mathrm{pH}=3$ e $18 \mathrm{~h}$ em $\mathrm{pH}=7$. A energia de superfície foi calculada através da determinação dos ângulos de contacto pela técnica de Wilhelmy. Foram realizados testes de resistência adesiva à microtração numa máquina de testes universal (Instron; 1 $\mathrm{mm} / \mathrm{min} ; 1 \mathrm{KN}$ ) e as superfícies de falha foram classificadas segundo o tipo de união em adesiva, mista ou coesiva. Os dados foram analisados estatisticamente com testes não paramétricos Mann-Whitney, exceto para o tipo de falha (qui-quadrado e exato de Fisher) ( $p=0,05)$. Resultados: Não foram encontradas diferenças estatisticamente significativas $(p>0,05)$ nos valores de energia de superfície em qualquer um dos materiais estudados após envelhecimento químico. A incorporação de CHX não influenciou de forma significativa a resistência adesiva nos espécimes de Kooliner e Ufi Gel Hard ( $p>0,05)$. Relativamente ao Probase Cold, a incorporação com 5\% de CHX conduziu a uma diminuição dos valores de adesão $(p=0,004)$ comparativamente ao controlo ( $0 \% \mathrm{CHX}$ ). Não foram encontradas diferenças estatisticamente significativas $(p>0,05)$ nos tipos de falha nas três resinas. Conclusões: Após envelhecimento químico, o sistema de libertação de $\mathrm{CHX}$ em todas resinas não parece afetar a energia de superfície. A incorporação de CHX, não parece afetar a resistência adesiva do Kooliner e Ufi Gel Hard, mas influenciou negativamente a adesão do Probase Cold com 5\% de CHX.

http://doi.org/10.24873/j.rpemd.2019.12.599

\section{\#140 Estudo comparativo da análise polissonográfica e tomográfica das vias aéreas superiores}

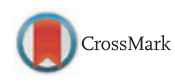

Helena Sofia Gomes Files*, Maria Cristina Pollmann, Eugénio Martins

Faculdade de Medicina Dentária da Universidade do Porto

Objetivos: Comparar dados respiratórios, obtidos por polissonografia, com variáveis cefalométricas e dimensões das vias aéreas, através da tomografia computadorizada de feixe cónico, em crianças com diagnóstico preliminar de apneia. Materiais e métodos: Selecionaram-se cinco crianças dos dezassete aos dezanove anos, com suspeita de síndrome da apneia obstrutiva do sono, através do preenchimento do questionário pediá- trico do sono pelos seus pais. Posteriormente, obteve-se o diagnóstico preliminar positivo para a síndrome da apneia obstrutiva do sono através do estudo polissonográfico. O estudo das vias áreas foi obtido com recurso a tomografia computadorizada de feixe cónico. O estudo cefalométrico foi produzido pelo programa Nemotec Dental Studio ${ }^{\circledR}$. A análise estatística foi obtida através do software SPSS. Resultados: O grupo analisado apresenta biótipo braquifacial com grau de severidade médio. Verificaram-se correlações estatisticamente significativas do índice de apneia obstrutiva com a frequência cardíaca média $(R=0.954, p=0.012)$, índice de apneia/hipopneia $(R=0.937, p=0.019)$, duração média de hipopneias $(R=$ -0.938, $\mathrm{p}=0.018)$ e o ângulo SNB ( $\mathrm{R}=-0.836, \mathrm{p}=0.077)$. Na correlação do volume das vias áreas com outras variáveis, o volume apresentou correlações positivas e significativas com o total de episódios de ronco $(\mathrm{R}=0.911, \mathrm{p}=0.089)$, duração média do ronco $(R=0.911, p=0.089)$, índice de dessaturação $(R=0.913$, $\mathrm{p}=0.087)$, índice de apneia/hipopneia $(\mathrm{R}=0.922, \mathrm{p}=0.078) \mathrm{e}$ ângulo ANB ( $\mathrm{R}=0.906, \mathrm{p}=0.094)$. Na área de secção máxima com o índice de apneias mistas, a correlação foi positiva e significativa $(R=0.968, p=0.032)$. Conclusões: $A$ amostra deste estudo foi caraterizada como braquifacial e com tendência para a classe I esquelética. No entanto, estudos adicionais são necessários para validar a metodologia aplicada.

http://doi.org/10.24873/j.rpemd.2019.12.600

\section{\#141 Avaliação de particulados dentinários com diferentes espessuras de dentina}

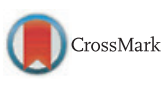

Mariana Rodrigues Viana da Silva Pereira*, Maria Leonor Dias Lourenço Balsinha, Sandra Carvalho, Inês Côrte-Real, Paula Vaz, João Carlos Sampaio Fernandes

Departamento de Física da Universidade de Minho, Faculdade de Medicina Dentária da Universidade do Porto

Objetivos: Nos últimos anos, as propriedades físico-químicas dos biomateriais têm sido estudadas com o propósito de identificar características que potenciem os resultados clínicos da regeneração óssea. Entre estas características, a granulometria e a composição química do biomaterial destacam-se por influenciarem a atividade e velocidade de reabsorção do biomaterial. (Calvo-Guirado JL et al., 2019) Considerando a avaliação destas propriedades em particulados dentinários obtidos por trituração de dentes extraídos e por representarem um potencial material de enxerto autógeno, este estudo pretende analisar as diferenças morfológicas e químicas obtidas a partir de dentes com diferentes espessuras da camada dentinária. Materiais e métodos: Para a realização deste estudo foram utilizados duas peças dentárias íntegras, um incisivo central superior e um canino, triturados com a Smart Dentin Grinder ${ }^{\mathrm{TM}}$, segundo o protocolo do fabricante. Neste processamento dentário foi adotado um tempo de trituração de 3 segundos, seguido de um tempo de vibração de 20 segundos, de forma a se obterem partículas entre os 300 e $1200 \mu \mathrm{m}$. A morfologia do particulado dentinário obtido foi avaliada por microscopia eletrónica de varrimento (NanoSEM - FEI Nova 200 (FEG/SEM)). Enquanto o estudo da composição química das amostras foi efetuado através de EDS (EDAX - Pegasus X4M). 
Resultados: A análise por microscopia eletrónica permitiu identificar diferenças no tamanho das partículas consoante a amostra considerada, tendo-se constatado um tamanho inferior quando considerado o dente incisivo (de 1,01 mm- 211,84 $\mu \mathrm{m}$ para 158,32-906,45 $\mu \mathrm{m}$ ). Relativamente à morfologia, em ambas as amostras, esta é idêntica, com distinção de uma camada externa correspondente ao esmalte e uma camada interna correspondente à dentina. Contudo, a camada externa no incisivo apresentou mais poros, sendo estes mais definidos e em maior número. A análise por EDS demonstrou uma semelhança em termos de elementos químicos presentes em ambas as camadas, embora a camada interna na amostra obtida do incisivo tenha apresentado uma maior quantidade de cálcio. Conclusões: A espessura dentinária parece determinar as diferenças topográficas e químicas detetadas. No entanto, o desenvolvimento de estudos adicionais torna-se pertinente no sentido de esclarecer a influência que esta característica poderá desempenhar no sucesso da regeneração óssea.

http://doi.org/10.24873/j.rpemd.2019.12.601

\section{\#142 Comparação topográfica e química de particulados dentinários com e sem resina composta}

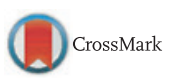

Daniela Filipa dos Santos Silva*, Mariana Azevedo Melo, Sandra Carvalho, Inês Côrte-Real, Paula Vaz, João Carlos Sampaio Fernandes

Departamento de Física da Universidade de Minho, Faculdade de Medicina Dentária da Universidade do Porto

Objetivos: Vários biomateriais têm sido desenvolvidos para promover a regeneração óssea, sendo que, a possibilidade de utilização de dentes extraídos como um material de enxerto autólogo tem sido proposta. O dispositivo Smart Dentin GrinderTM (Calvo-Guirado JL et al., 2018) foi concebido com este propósito permitindo o fabrico do material de enxerto por trituração dentária. Contudo, previamente a este procedimento um dos cuidados clínicos protocolados pressupõe a remoção prévia de qualquer material artificial da superfície dentária, como a resina composta. Como tal, este estudo tem como objetivo avaliar a existência de diferenças na topografia e composição química de particulados dentinários, obtidos após a moagem de dentes para posterior utilização como material de enxerto, consoante a presença ou ausência de resina composta. Materiais e métodos: Para a realização deste estudo foram utilizados dois dentes incisivos centrais superiores, um deles íntegro (sem qualquer material artificial adicionado) e o outro restaurado com resina composta. Os dentes foram processados com a Smart Dentin Grinder ${ }^{\mathrm{TM}}$, segundo o protocolo do fabricante. Para este processamento dentário foi considerado uma trituração de 3 segundos, seguida de uma fase de vibração de 20 segundos para que fossem obtidas partículas entre os 300 e $1200 \mu \mathrm{m}$. A análise da morfologia do particulado dentinário obtido foi efetuada por microscopia eletrónica de varrimento (NanoSEM - FEI Nova 200 (FEG/SEM)). A composição química das amostras foi identificada através de EDS (EDAX - Pegasus $\mathrm{X} 4 \mathrm{M})$. Resultados: Pelas análises de microscopia eletrónica constatou-se que o tamanho das partículas na amostra com resina composta $(1,37 \mathrm{~mm}-300,67 \mu \mathrm{m})$ é menos uniforme comparativamente à amostra íntegra (158,32-906,45 $\mu \mathrm{m})$, existindo uma maior variabilidade relativamente ao tamanho das mesmas. Em ambas as amostras são detetáveis os túbulos dentinários, mas nas zonas com resina composta tornam-se menos percetíveis (parecendo estarem recobertos) e, por isso, aparentando serem menos profundos. A análise da composição química na amostra com resina composta detetou uma expectável maior quantidade de carbono. Conclusões: A manutenção de resina composta nos dentes selecionados para serem processados em material de regeneração óssea autógena condiciona alterações topográficas e químicas, que devem ser exploradas em estudos futuros, no sentido de compreender se as mesmas poderão interferir no processo de osteointegração. http://doi.org/10.24873/j.rpemd.2019.12.602

\section{\#144 Terapias de extração parcial: revisão sistemática e meta-análise}

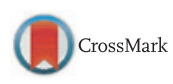

Miguel Pimenta*, Tiago Nunes, Francisco Caramelo, João Paulo Tondela

Faculdade de Medicina Universidade de Coimbra

Objetivos: Após a extração dentária desencadeiam-se mecanismos fisiológicos multifatoriais que conduzem a reabsorção óssea e remodelação alveolar. Em zonas anteriores estas alterações tridimensionais do rebordo alveolar interferem frequentemente com o resultado estética das reabilitações implanto-suportadas. Existem diversas técnicas desenvolvidas para minimizar as alterações tecidulares pós-extração e compensar as alterações dimensionais, apesar de nenhuma técnica cirúrgica ou nenhum material previna completamente essas alterações. As terapias de extração parcial foram recentemente desenvolvidas com o objetivo de prevenir a reabsorção da tábua óssea vestibular.<br/>Este trabalho pretende fazer uma revisão sistemática e meta-análise para a avaliação da perda de osso em implantes colocados em alvéolos sujeitos às técnicas de extração parcial. Materiais e métodos: Realizou-se uma pesquisa bibliográfica na PubMed/MEDLINE e na Cochrane Library com a seguinte chave de pesquisa: ('socket-shield' OR "root membrane") AND (implant OR dental OR ridge OR esthetics), usando como filtros publicações em inglês ou português até ao Maio de 2019. Não foram feitas restrições sobre o tipo de publicação. Foi realizada uma análise estatística utilizando o pacote "Metafor". Resultados: Obteve-se um total de 49 artigos dos quais foram selecionados 8 para leitura integral, após exclusão dos duplicados e leitura do título e resumo. Desses artigos, sete foram incluídos para esta revisão sistemática. Os estudos incluíram um total de 431 pacientes e 511 implantes colocados de acordo com as técnicas de extração parcial. A meta-análise mostrou uma perda de osso de 0,29 mm; 95\% CI: 0,05 a 0,52 mm. Conclusões: Dentro das limitações desta revisão, pode ser concluído que as terapias de extração parcial em conjunto com a colocação de implantes imediatos podem prevenir eficazmente a perda de osso marginal e consequentemente, manter a estética dos tecidos moles.

http://doi.org/10.24873/j.rpemd.2019.12.603 